\title{
How do medical students use and understand pain rating scales?
}

\author{
Pardis Zalmay ${ }^{\mathrm{a}} \mathrm{BSc}$
}

Amanda C de C Williams ${ }^{b}$ BSc MSc PhD CPsychol

\author{
a UCL Medical School \\ University College London \\ Gower St, London WC1E 6BT, UK \\ Email pardis.zalmay.12@ucl.ac.uk \\ Phone +447576482392 \\ b Research Dept of Clinical, Educational \& Health Psychology \\ University College London \\ Gower St, London WC1E 6BT, UK \\ Email amanda.williams@ucl.ac.uk \\ Phone +442076791608
}

Corresponding author: Amanda C de C Williams

18 pages

Text 2592 words excluding references

No tables or figures

One supplementary file 


\section{How do medical students use and understand pain rating scales?}

\section{Abstract}

Background and aims: Pain is a multidimensional experience that is hard to describe and to measure, with many personal and contextual influences on self-ratings or on estimates of others' pain. Clinicians tend to underestimate patients' pain, more so with longer experience, so medical students' estimation of others' pain as they gain clinical experience is of interest, as is the influence of their personal experience on self-ratings and on estimates of others' pain.

Methods: We presented medical students in their clinical years with questions online about their own and others' worst pain and its causes, how they interpreted the upper end of the pain scale, and their preferences among pain rating scales.

Results: Medical students were more likely to rate the worst pain observed in another as significantly higher than their own worst pain only when they rated observed worst pain after rather than before their own. Their descriptions of behaviour indicating maximum pain, although relevant (such as facial and vocal expression), showed considerable variability.

Conclusions and implications: The findings raised several important questions that could inform further research on this topic. At a minimum, encouraging clinicians to refer to their own severe pain experiences may partly mitigate underestimation of others' pain.

Keywords: pain estimation, pain behaviour, pain expression, numerical rating scale, worst pain 


\section{Extended summary}

Background and aims: Pain is a multidimensional experience that is difficult to describe and to assess. To scale current pain, assessment refers to a maximum level of pain, but little is known about this proces. Further, clinicians tend to underestimate patients' pain, with or without patients' own reports, and to underestimate to a greater extent with more clinical experience, possibly due to recalibration of a personal pain scale with increasing exposure to severe pain. We sought to determine how medical students rated pain in early years of clinical exposure, and in relation to experience of their own and others' worst pains.

Methods: An online survey sampled medical students' rating and description of their own worst pain and of that witnessed in another; also what would cause the maximum level of pain and what behaviours characterised it. Last, they indicated their preference among pain scales.

Results: Thirty-six medical students provided responses, the majority in their first six months of clinical exposure. Students' own worst pain was rated a mean of $6.7 / 10$ (s.d. 1.6) on a numerical scale; causes were diverse but with many bone fractures. Mean worst pain observed in another was rated 8.6/10 (s.d. 1.4); causes included fractures, gallstones, and sickle cell crises. Another's worst pain was significantly higher (mean 9.4, s.d. 0.8 vs mean 8.0 s.d. 1.4) when rated after the student's own pain than before it (presentation order randomised).

We found no effect of clinical exposure on estimation of worst pain in another person, nor was there a personal tendency to rate pain using more or less extreme values. Students expected pain of $10 / 10$ to be presented with many verbal, facial and whole body behaviours, and signs of physiological stress. Collectively, behavioural descriptions were rich and varied, but with many incompatibilities: for instance, between 'writhing' and 'rigidity' expected in the person with extreme pain. Most students preferred the numerical rating scale over visual analogue and verbal scales.

Conclusions: The study requires replication, particularly for clinical experience, where we found no significant difference in estimation of 
another's pain over the first three years of medical students' clinical exposure, but the comparison was underpowered. Despite no systematic individual difference in using pain ratings, there was a marked effect of rating another's worst pain higher when the rater had previously rated his/her own worst pain. This suggests anchoring estimate of another's pain in personal pain experience, and a possible way to mitigate clinicians' underestimation of patients' pain.

Medical students' recognition of the importance of facial expression in indicating another's pain severity was encouraging, but most students anticipated only a narrow range of behaviours associated with extreme pain, thereby excluding other authentic behaviours.

Implications: Many clinical guidelines mandate regular pain assessment for hospital inpatients, and encourage routine assessment in community and outpatient settings, in order to decide on and monitor treatment. Replication and elaboration of this study could extend our understanding of how clinicians interpret pain scales completed by patients, and how they estimate patients' pain.

\section{Highlights}

1. Medical students refer to their own worst pain when rating another's afterwards.

2. Medical students' clinical exposure did not affect pain estimates.

3. Facial expression was the most frequently reported indicator of maximum pain.

4. Medical students preferred the numerical rating scale over other pain scales. 


\section{Introduction}

The widely accepted pain definition, 'an unpleasant sensory and emotional experience associated with actual or potential tissue damage, or described in terms of such damage' [1], has an accompanying note emphasising subjectivity of pain and the central place of self-report. There is no necessary association between physical findings and intensity of pain, particularly in chronic pain [2, 3]. Given common processes, whatever its origins, chronic pain could arguably be considered a disease in its own right, without reference to presumed pathology [4].

Multiple pain self-report methods are in common use, in clinical and research settings [5, 6]; commonest are the visual analogue scale (VAS), numerical rating scale (NRS), and verbal rating scale (VRS) [6, 7]. All are generally described as having satisfactory reliability, validity and sensitivity to change $[8,9]$, with thoughtful methods of deriving cutpoints or percentages of clinically significant change with treatment $[10,11]$. However, there is no agreement on important elements such as the timescale for the rating [12], nor the wording of the crucial upper limit [5], and little is known of the internal processes or external influences by which the person in pain approximates that multidimensional experience in a unidimensional score [13, 14, 15].

Independent of self-report, observers, particularly clinicians, make their own estimations of pain in others. While this can be helpful for those who are unable to report their pain (through cognitive underdevelopment or impairment), it is subject to systematic biases [16], commonly underestimation $[17,16]$. These biases may arise from patient characteristics such as sex, ethnicity, and status $[18,19,16]$; presence or absence of medical evidence 
[20]; or from observer characteristics such as doubt about the authenticity of pain [21], empathy [22], or length of experience [17]. These biases are somewhat resistant to correction by exposure to the patient's rating [23]. Treatment decisions [24, 25] may be based on irrelevant information [26] although facial expression offers a reliable basis for observational judgement [27].

However, little is known about how clinicians' own experience informs their estimation of others' pain, and their interpretation of the upper end of pain intensity scales. Estimation of others' pain tends to become more conservative with experience [17], possibly because clinicians recalibrate internal reference points as they become habituated to observing intense pain through clinical experience [28]. We investigated possible bias in medical students' ratings of pain in their early exposure to clinical experience; in relation to their personal experience of pain; and to their exposure to patients' pain. Specifically, we asked:

1 Is there individual bias to higher or lower ratings for students' own pain?

2 Does increasing exposure to patients produce lower ratings of others' pain? 3 Is there a relationship between rating of students' own worst pain and others' worst pain?

4 What do students look for in others to indicate maximum pain?

\section{Materials and Methods}

Ethics approval was granted by the University Departmental Ethics Committee (UCL CEHP/2014/527). UCL medical students in years 4 to 6 , 
their first three years of intensive clinical exposure, were recruited via advertising on UCL medical student Facebook pages and through social networks. Using the ANOVA power calculator, a medium effect size of $F=$ 0.5 , an $\alpha$ error probability of 0.05 , and an estimated power of 0.811 , a minimum sample size of 27 was calculated [29].

The invitation to participate contained a link to an online survey presented using Qualtrics survey software [30]. Following information about the survey, consent consisted of clicking on 'Yes, I wish to take part in the survey'. First, the participant was asked if s/he was a medical student, and in which year. Then there followed 8 forced-choice and 4 free-response questions, the latter provided with an expandable text box (see Supplementary File).

The questions fell into three main areas: the participant's own experience of pain ( ${ }^{*}$ cause of own worst pain, rating of worst pain experienced on NRS, *what would pain rated 10 feel like if participant had not rated own worst pain 10/10; rating of most recent vaccination on NRS; rating of worst pain on VRS; rating of worst pain experienced on VAS); ranked preference of the three scales; the participant's experience of worst pain in another person ( ${ }^{*}$ cause of worst pain observed in another person, estimation of that pain on NRS, and *how the participant would know when another person was experiencing pain of $10 / 10$ ). There were two orders of questions (questions about the participant's pain before or after those about observed pain), assigned to participants at random order.

The NRS presented for self and other had the anchors 'no pain' at 0 and 'extreme pain' at 10 . The VAS was a single line with a movable slider to mark the point representing pain, with the same anchors as the NRS. The VRS 
used the following unnumbered but ordered categories: no pain, mild pain, moderate pain, severe pain, very severe pain.

Data were collected automatically by the Qualtrics system and downloaded as an Excel file. Quantitative data were checked for normal distribution (using the Kolmogorov-Smirnov test) and appropriate tests applied [31]. Qualitative data from free text responses were analysed using concepts from thematic analysis [32] but were not sufficiently rich for full thematic analysis. Repeated themes and meanings were sought in reading and re-reading responses, and were independently categorised by both authors who then reached consensus.

A technical error occurred for the worst pain rating using the VAS: disabling the numeric component of the slider (since visible numbers would have changed the VAS into a numerical scale) caused failure of data recording. This was not anticipated by the technical support team and has been reported to the software designers.

\section{Results}

\subsection{Participants}

39 participants were recruited; of these, 3 dropped out without providing any information other than their year of study. Sex and ethnicity were not requested. Twenty participants were in their $4^{\text {th }}$ year of study with about four months in hospital settings, 11 in their $5^{\text {th }}$ year with about 13 months in hospital, and five in their $6^{\text {th }}$ year with about 21 months of hospital experience; 
six provided incomplete information, leaving 30 complete data entries, although partial data were used where possible.

\subsection{Own worst pain}

34 participants described their own worst pain, caused in ten cases by fractures and otherwise diverse causes (such as menstrual cramping, back muscle spasms, kidney stones, and gout). Mean own worst pain was 6.73 , s.d. 1.64, on the NRS, with no difference according to whether it was asked before or after other's worst pain, and the verbal scale was rated by 31 of the 34 as very severe, severe by 18 , and moderate by 8 .

Question 1: Is there individual bias to higher or lower ratings for students' own pain? We correlated participants' rating of the pain of their most recent vaccination (mean 1.59/10, s.d. 1.35), since that is a relatively frequent event for medical students), with their worst pain, but there was no linear correlation between scores (Pearson's $r=0.112, n s$ ), nor did a plot suggest a nonlinear relationship.

In response to the question on what pain would feel like that the participant would rate $10 / 10$ (a rating used by only one of the 30 participants who answered this), eight referred to specific painful events such as childbirth, extensive burns, or fractures; five provided other physical referents such as intense heat; two identified emotional events such as death of a close family member; and 12 used emotional terminology such as "unbearable" (3 participants), "unrelenting" (2 participants) and "excruciating" (2 participants); remaining comments could not be classified.

\subsection{Worst pain seen in another}


The mean for the worst pain observed in another was 8.61, s.d.1.38, a mean of 1.88 higher than own worst pain: Wilcoxon signed rank test, $Z=3.922, p<$ 0.01. Causes of the worst pain rated were again diverse, with 10 describing fractures, gall stones, pregnancy, sickle cell crises, a ruptured spleen, and neuropathic pain. There was an order effect for other's worst pain, with a significantly higher mean rating for those who rated other's worst pain after their own worst pain 9.43 (s.d. 0.76 ) versus 7.94 (s.d. 1.44): $t=3.49, p=$ 0.002 .

Question 2: Does increasing exposure to patients produce lower ratings of others' pain? Year of study was unrelated to the scores given for other's worst pain: Spearman's $\rho=0.087$, ns.

Question 3: Is there a relationship between rating of students' own worst pain and others' worst pain? There was no linear correlation between own worst pain rating and other worst pain rating: Spearman's $\rho=0.040$, ns.

Question 4: What do students look for in others to indicate maximum pain? To the question on what pain of 10/10 would look like in another, 31 responses provided rich and multiple descriptions in several aspects of behaviour: 18 described vocal expression (five mentioned "crying"; others included "screaming", "shouting", "asking to put an end to their misery", "silence", "inability to communicate"); 17 mentioned facial expression ("facial expression of agony", "screwed up face"); seven referred to movement or lack of movement ("body position", "writhing around", "extreme restlessness", "complete rigidity to avoid movement"); seven referred to other physiological phenomena (such as sweating, paleness, increased heart rate and blood 
pressure, "drifting in and out of consciousness"); and six to respiratory distress ("difficulty in breathing", "tachypnoeic", "gasping in agony").

\subsection{Preference for rating scale}

Asked their preference for pain rating scale, 17 (55\%) opted for the NRS, eight (26\%) for the VAS, and six (19\%) for the VRS.

\section{Discussion}

We did not find any systematic personal bias towards higher or lower ratings, either for rating own pain or for estimating others' pain. Nor was there any overall tendency to anchor estimation of another's worst pain in the medical student's own worst pain experience, but there was a marked effect of order of asking these questions, with higher estimates of another's worst pain for those who rated it after, rather than before, their own; this suggests that there is some relationship between the two.

Nor was there the widely hypothesised relationship [33, 34] between increasing exposure to others' pain in clinicians and lower estimates of those others' pain, as a result of constant recalibration of one's personal pain scale with each new exposure to high levels of pain in patients [34]. However, sample size in the more clinically exposed groups meant that this test was underpowered, so our findings are tentative.

Medical students were able to provide a wide range of behaviours that would indicate maximum pain to them when seen in another person; many students provided several specific descriptors. When the descriptors were grouped into behavioural domains, opposite behaviours were contained within the same 
domain: for example, writhing around vs complete rigidity; screaming vs silence.

It was encouraging to see that facial expression was the behaviour most frequently proposed (it had been taught to the medical students in an earlier year), closely followed by vocal distress. Both are observable in patients who are not verbal or may have cognitive impairment, and whose pain risks being overlooked $[35,36]$. Detecting that another person finds his or her pain 'unbearable', or 'excruciating' is not necessarily easy, and dependence on particular behaviours, whether respiratory, facial, bodily or vocal, may have poor sensitivity and specificity, given what is understood about the multiple influences on people's behaviour when in pain, including in clinical settings [37]. In practice, pain estimation does not necessarily take into account the behaviours that observers report using to estimate pain [37], so we cannot comment on how these medical students performed in pain estimation in clinical settings.

There was also rich use of emotional terms in describing the experience of maximum pain, even where specific injuries such as fractures were described for own worst pain: for instance, a participant who identified a dislocated shoulder, rated $8 / 10$, as his or her worst pain described the experience of pain of $10 / 10$ as "excruciating". Fractures were highly represented among causes of maximum pain, as was childbirth, reflecting beliefs about expected levels of pain according to the tissue damage or stress [38].

Preference for the NRS over other pain rating scales were close to those of chronic pain patients in another study [14], although the main hospital where many medical students will have had clinical experience uses a 5 point VRS. 
Although we found no evidence for the habituation hypothesis of increasing underestimation of patients' pain [17] with increasing clinical experience, this question requires replication in larger samples, and in junior doctors with direct responsibility for assessing and treating patients. Alternative hypotheses, such as that of cheater detection [17], also require further testing. It may be that details of setting, such as whether patients are seen only once or repeatedly [40], and characteristics [41] and experience of the clinician, are important mediators of the effects of exposure. It did appear that rating worst self-pain before estimating worst pain of another may have anchored the estimate of another's pain in the rater's own experience and produced a higher other-pain estimate.

We are also unaware of any systematic teaching for clinicians on estimation of patients' pain, other than in the use of particular behavioural scales [35], and participants in our study tended to use beliefs about pain expression rather than their own direct or observed experience of pain to inform their expectations of patients with very high levels of pain. It may be that different pains are associated with different behaviours, perhaps fracture with stillness and visceral pain with writhing: this is an unexplored area of behaviour in acute pain.

\section{Strengths and limitations}

Although the sample size met that required, it was still a small sample of the entire medical cohorts in these years and is unlikely to be representative. Using an online questionnaire to collect data allowed a wider pool of possible recruits than face-to-face recruitment [39], particularly given the dispersal of medical students in their clinical years. It also reduces social desirability bias 
associated with face-to-face questioning. On the other hand, recruitment in person may increase numbers and reduce attrition, and allows clarification if required.

Variable ordering of questions was used to reduce the likelihood that relationships between pain ratings and estimates were biased by a fixed order [23], and yielded an interesting order effect between own worst pain rating and other worst pain estimate. However, participants were not asked their age, gender or ethnicity, and gender in particular has been associated with differences in pain ratings and pain estimates [16, 19], so we cannot be sure that differences are not attributable to sociodemographic variables.

\section{Conclusions}

We found partial support for one of our hypotheses: despite not finding any individual bias towards using higher or lower ratings for pain in general, estimation of another's worst pain was influenced by rating of own worst pain only when own worst pain was rated before, not after, another's worst pain. We did not find the hypothesised effect of exposure to clinical pain experience on lowering estimates of others' pain, but this comparison was underpowered. Although, collectively, medical students provided rich descriptions of behaviour that can indicate severe pain, individually many accounts were rather narrow and thus of limited use.

\section{Implications}

Despite the ubiquity of pain rating scales and exhortations that they should be used routinely in patient care, we still know relatively little about how they are used and interpreted by clinicians. Clinicians on their part are sceptical about 
the value of pain ratings [42], and we endorse the call for more attention to this important issue for clinical care and research studies.

Conflict of interest: Neither of the authors has any conflict of interest to declare.

Ethical issues: please see details at beginning of Methods. Informed consent was required and provided; ethical approval was obtained; the study was registered internally at UCL but not on any external database. 


\section{References}

[1] IASP (International Association for the Study of Pain). Pain terms, a current list with definitions and notes on usage. 1994. http://www.iasppain.org/Taxonomy\#Pain accessed $12^{\text {th }}$ October 2016.

[2] Melzack R, Wall PD. Pain mechanisms: a new theory. Science 1965;150(3699):971-9.

[3] Woolf CJ. What is this thing called pain? J Clin Investigation 2010;120(11):37424.

[4] Tracey I, Bushnell MC. How neuroimaging studies have challenged us to rethink: is chronic pain a disease? J Pain 2009;10(11):1113-20.

[5] Hjermstad MJ, Fayers PM, Haugen DF, Caraceni A, Hanks GW, Loge JH, Fainsinger R, Aass N, Kaasa S. Studies comparing Numerical Rating Scales, Verbal Rating Scales, and Visual Analogue Scales for assessment of pain intensity in adults: a systematic literature review. J Pain Symptom Manage 2011;41(6):1073-93. doi:10.1016/j.jpainsymman.2010.08.016

[6] Litcher-Kelly L, Martino SA, Broderick JE, Stone AA. A systematic review of measures used to assess chronic musculoskeletal pain in clinical and randomized controlled clinical trials. J Pain 2007;8(12):906-13. doi:10.1016/j.jpain.2007.06.009

[7] Jensen MP, Karoly P. Self-report scales and procedures for assessing pain in adults. In: Turk DC, Melzack R (eds), Handbook of pain assessment, $3^{\text {rd }}$ edition. New York, Guilford Press, 2011, pp. 9-44.

[8] Ferreira-Valente MA, Pais-Ribeiro JL, Jensen MP. Validity of four pain intensity rating scales. Pain 2011;152(10):2399-404. doi:10.1016/j.pain.2011.07.005

[9] Wood BM, Nicholas MK, Blyth F, Asghari A, Gibson S. Assessing pain in older people with persistent pain: the NRS is valid but only provides part of the picture. J Pain 2010;11(12):1259-65. doi:10.1016/j.jpain.2010.02.025

[10] Boonstra AM, Schiphorst Preuper HR, Balk GA, Stewart RE. Cut-off points for mild, moderate, and severe pain in patients with chronic musculoskeletal pain. Pain 2014;155:2545-50. doi: 10.1016/j.pain.2014.09.014

[11] Farrar JT, Portenoy RK, Berlin JA, Kinman JL, Strom BL. Defining the clinically important difference in pain outcome measures. Pain 2000;88: 287-94.

[12] Stone AA, Schneider S, Broderick JE, Schwartz JE. Single-day pain assessments as clinical outcomes: not so fast. Clin J Pain 2014;30:739-43.

[13] Broderick JE, Stone AA, Calvanese P, Schwartz JE, Turk DC. Recalled pain ratings: a complex and poorly defined task. J Pain 2006;7:142-9.

[14] Williams ACDC, Davies HTO, Chadury Y. Simple pain rating scales hide complex idiosyncratic meanings. Pain 2000;85:457-63. doi:10.1016/S03043959(99)00299-7

[15] Hodgins M. Interpreting the meaning of pain severity scores. Pain Res Manage 2002;7(4): 192-8.

[16] Tait RC, Chibnall JT, Kalauokalani D. Provider judgments of patients in pain: seeking symptom certainty. Pain Med, 2009;10:11-34.

[17] Kappesser J, Williams ACDC. Pain estimation: asking the right questions. Pain 2010;148(2):184-7. doi:10.1016/j.pain.2009.10.007 
[18] Green CR, Anderson KO, Baker TA, Campbell LC, Decker S, Fillingim R, Kaloukalani DA, Lasch KE, Myers C, Tait RC, Todd KH, Vallerand AH. The unequal burden of pain: confronting racial and ethnic disparities in pain. Pain Med 2003;4:277-94.

19] Schäfer G, Prkachin KM, Kaseweter KA, Williams ACDC. Health care providers' judgments in chronic pain: the influence of gender and trustworthiness. Pain 2016;157(8):1618-25. doi: 10.1097/ j.pain.0000000000000536.

[20] De Ruddere L, Goubert L, Stevens M, Williams ACdeC, Crombez G. Discounting pain in the absence of medical evidence is explained by negative evaluation of the patient. Pain 2013;154(5):669-76. doi:10.1016/j.pain.2012.12.018

[21] Kappesser J, Williams ACDC, Prkachin KM. Testing two accounts of pain underestimation. Pain 2006;124:109-116. doi:10.1016/j.pain.2006.04.003

[22] Green AD, Tripp DA, Sullivan MJL, Davidson M. The relationship between empathy and estimates of observed pain. Pain Med 2009;10: 381-92.

[23] Riva P, Rusconi P, Montali L, Cherubini P. The influence of anchoring on pain judgment. J Pain Symptom Manage 2011;42(2): 265-76.

[24] Michael GE, Sporer KA, Youngblood GM. Women are less likely than men to receive prehospital analgesia for isolated extremity injuries. Amer J Emerg Med 2007;25(8):901-6. doi:10.1016/j.ajem.2007.02.001

[25] Staton LJ, Panda M, Chen I, Genao I, Kurz J, Pasanen M, Mechaber AJ, Menon M, O'Rorke J, Wood J, Rosenberg E, Faeslis C, Carey T, Calleson D, Cykert S. When race matters: disagreement in pain perception between patients and their physicians in primary care. J Nat Med Assoc 2007;99(5):532-8.

[26] Kim HS, Schwartz-Barcott D, Tracy SM, Fortin JD, Sjöström B. Strategies of pain assessment used by nurses on surgical units. Pain Manage Nurs 2005;6(1):3-9. doi:10.1016/j.pmn.2004.12.001

[27] Williams ACDC, Craig K. Editorial: A science of pain expression? Pain 2006;125:202-3.

[28] Prkachin KM. Facial pain expression. Pain Manage 2011;1:367-376. doi:10.2217/pmt.11.22

[29] Paul F, Erdfelder E. (1992).GPOWER: A priori-, post hoc-, and compromise power analyses for MS-DOS [computer program]. Bonn, Germany: Bonn University. http://rd.springer.com/article/10.3758/BF03203630 accessed $31^{\text {st }}$ October 2016

[30] Qualtrics software. https://www.qualtrics.com/ accessed on 31 $1^{\text {st }}$ October 2016

[31] Treister R, Nielsen CS, Stubhaug A, Farrar JT, Pud D, Sawilowsky S, Oaklander AL. Experimental comparison of parametric versus nonparametric analyses of data from the cold pressor test. J Pain 2015; 16(6):537-48. doi: 10.1016/j.jpain.2015.03.001.

[32] Braun V, Clarke V. Using thematic analysis in psychology. Qualitative Research in Psychology. Taylor \& Francis, 2006. Retrieved from http://eprints.uwe.ac.uk/11735/2/thematic_analysis_revised_-_final.pdf 31st October 2016

[33] Helson $\mathrm{H}$. Current trends and issues in adaptation-level theory. Amer Psychologist 1964;19(1):26-38. 
[34] Prkachin KM, Mass H, Mercer SR. Effects of exposure on perception of pain expression. Pain 2004;111(1-2):8-12. doi:10.1016/j.pain.2004.03.027

[35] Hadjistavropoulos T, Breau LM, Craig KD. Assessment of pain in adults and children with limited ability to communicate. In: Turk DC, Melzack R (eds.), Handbook of pain assessment, $3^{\text {rd }}$ edition. New York, Guilford Press, 2011, pp. 260-280.

[36] Kunz M, Chatelle C, Lautenbacher S, Rainville P. The relation between catastrophizing and facial responsiveness to pain. Pain 2008;140(1):127-34. doi:10.1016/j.pain.2008.07.019

[37] Hadjistavropoulos T, Craig KD, Duck S, Cano AM, Goubert L, Jackson P, Mogil J, Rainville P, Sullivan M, Williams ACdeC, Vervoort T, Dever Fitzgerald T. A biopsychosocial formulation of pain communication. Psychol Bull 2011;137(6):910-39.

[38] Marco CA, Nagel J, Klink E, Baehren D. Factors associated with self-reported pain scores among ED patients. Amer J Emerg Med 2012;30:331-7.

[39] Garton L, Haythornthwaite C, Wellman B. Studying online social networks. J Computer-Mediated Commun 2006;3(1). doi:10.1111/j.10836101.1997.tb00062.x

[40] Kappesser J, Williams ACdeC. Pain and negative emotions in the face: Judgements by health care professionals. Pain 2002;99;197-206. doi:10.1016/S0304-3959(02)00101-X

[41] Drwecki BB, Moore CF, Ward SE, Prkachin KM. Reducing racial disparities in pain treatment: the role of empathy and perspective-taking. Pain 2011;152:1001-6.

[42] Backonja M, Farrar JT. Are pain ratings irrelevant? Pain Med 2015;16:1247-50. 


\section{Supplementary file: online questions to participants}

\section{$\mathrm{UC}$}

Do you study medicine?

Yes

No

What year of study are you in?

은

Back Next >

What was the cause of the worst pain you've witnessed in someone else?

How would you rate the worst pain you've witness in someone else on a scale of $0-10 ?$

No pain

Extreme pain

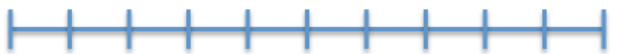

$\begin{array}{lllllllllll}0 & 1 & 2 & 3 & 4 & 5 & 6 & 7 & 8 & 9 & 10\end{array}$

$\begin{array}{lllll}1 & 2 & 3 & 4 & 5 \\ 0 & 0 & 0 & 0 & 0\end{array}$

How would you know if you were looking at someone who was experiencing a pain of rating of 10 ?

What was the cause of the worst pain you've experienced?

How would you rate the worst pain you've experience on a scale of $0-10$ ?

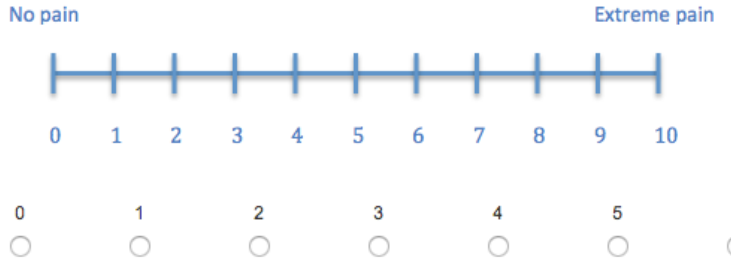

If you didn't choose 10 , what would you imagine pain that can be assigned to 10 would feel like? 
How would you rate the pain of your most recent vaccination on a scale of 0-10?

$\begin{array}{llllll}0 & 1 & 2 & 3 & 5\end{array}$

$\bigcirc$

10

$\bigcirc$

( 1

Please rate the worst pain you've experienced on this verbal rating scale:
No pain.
Mild pain
Moderate pain
Severe pain.
Very severe pain.

Please rate the worst pain you've experience on this visual analogue scale:
No pain
Extreme pain

Slider

Back Next >>

Please rank the three scales in order of preference:
Numerical Rating Scale
Verbal Rating Scale
Visual Analogue Scale

Back Next >> 